\title{
Correction to: Repugnant conclusions
}

\author{
Dean Spears ${ }^{1,2,3,4,5}$ - Mark Budolfson ${ }^{6,7,8}$
}

Published online: 23 April 2021

○ Springer-Verlag GmbH Germany, part of Springer Nature 2021

\section{Correction to: Social Choice and Welfare https://doi.org/10.1007/s00355-021-01321-2}

In the original publication of the article, the production team incorrectly processed the affiliations of the second author. The correct affiliation details are given below:

Department of Environmental and Occupational Health and Justice, Rutgers University, New Brunswick, USA

Center for Population-Level Bioethics, Rutgers University, New Brunswick, USA Department of Philosophy, Rutgers University, New Brunswick, USA

The original article has been corrected.

The original article can be found online at https://doi.org/10.1007/s00355-021-01321-2.

\section{Dean Spears}

dspears@utexas.edu

http://www.riceinstitute.org

1 Economics Department and Population Research Center, University of Texas at Austin, Austin, USA

2 Economics and Planning Unit, Delhi Centre, Indian Statistical Institute, New Delhi, India

3 IZA, Bonn, Germany

4 Institute for Futures Studies, Stockholm, Sweden

5 r.i.c.e, Lucknow, India

6 Department of Environmental and Occupational Health and Justice, Rutgers University, New Brunswick, USA

7 Center for Population-Level Bioethics, Rutgers University, New Brunswick, USA

8 Department of Philosophy, Rutgers University, New Brunswick, USA 